\title{
HACERLE ESPACIO AL MITO EN LA POLÍTICA
}

Recibido: 14-10-2016

Aprobado: 17-1-2017

\author{
Franklin Ibáñez \\ Universidad del Pacífico
}

\begin{abstract}
Doctor en Filosofía por la Pontificia Università Gregoriana (Roma). Actualmente profesor en la Pontificia Universidad Católica del Perú y la Universidad del Pacífico. Es autor de los libros "Pensar la justicia social hoy" (Roma 2014), "Globalización, justicia y pobreza" (Lima 2015). fe.ibanezb@up.edu.pe
\end{abstract}

\begin{abstract}
RESUMEN
El texto defiende la incorporación de los mitos en la política. Su exclusión se debe a tres motivos: son calificados como irracionales, no son suscritos por toda la población que conforma un Estado, y son obstáculos para el desarrollo económico. Sostendremos que tales motivos pueden relativizarse. Además la incorporación de los mitos puede significar una ganancia ética ante algunos problemas como la crisis ecológica.
\end{abstract}

Palabras clave: Mito, política, ecología, opinión pública.

ABSTRACT

This paper promotes to incorporate myths in politics. Myths have been excluded because three reasons: myths are seen as non rational, are not endorsed by whole society which forms a state, and might be obstacle to achive economic development. This paper debates those reasons. Also incorporation of myths might be a meaningful gain in terms of ethics specially to approach some issues as current ecological crisis.

Key words: Myth, politics, ecology, public opinion.

\section{INTRODUCCIÓN}

Hubo un tiempo en que no había distinción clara entre mito y realidad, o entre naturaleza y personas. Toda la realidad era mítica. Estaba cargada de fantasía y magia. El ser humano era el único testigo y protagonista en el espectáculo de vivir en un mundo encantado. La realidad estaba llena de sentido. Los mitos orientaban la convivencia, los senderos de lo bueno y lo justo. Conviene advertir que no se debe idealizar o descartar por completo el pasado mítico. Tales mundos pueden ser ciertamente añorados. A diferencia del mundo contemporáneo, los mitos cuidaban la naturaleza, en gran parte subrayando el vínculo entre humanidad pueblo o étnica concreta- y naturaleza. A la vez, también pueden ser criticados desde concepciones ético-políticas contemporáneas. Por 
ejemplo, diversos mitos justificaban la subordinación de las mujeres frente a los hombres.

Hoy, para una gran parte de la humanidad, el encanto se rompió. El hechizo del mito se debilitó. Apareció la razón, la crítica. Algunos humanos aprendieron a concebirse distintos del mundo natural. Frente a la naturaleza, se instaló una distancia infranqueable: el ser humano se volvió sujeto; la naturaleza, objeto. Las llamadas democracias contemporáneas han relegado el mito desde los espacios públicos hacia mundos privados. El mito pierde valor frente a los argumentos racionales al deliberar sobre asuntos de interés común que den origen a decisiones vinculantes. El mito sirve poco para la política.

El objetivo del presente texto es debatir la pertinencia de los mitos, los relatos de sentido de los pueblos ancestrales, en las discusiones políticas. Por un lado, los argumentos relacionados a los mitos han sido relegados en las deliberaciones políticas de la mayor parte de las democracias contemporáneas. Los motivos para descartar argumentos míticos serían tres. Primero, su carácter irracional desde cierta concepción dominante de lo que es racional. Segundo, su vínculo a un pueblo o cultura particular, de modo que no pueden ser reconocidos como universales. Tercero, su visión proteccionista de la naturaleza conlleva un freno al progreso económico. El mito en la política deviene extraño. Al primer argumento podríamos calificarlo especialmente como epistemológico; al segundo, político; al tercero, económico. Por otro lado, tales motivos son discutibles. La concepción dominante de racionalidad es estrecha y, aunque se pretenda universal, no escapa tampoco a su vínculo a una cultura particular-digamos, occidente moderno. Juzgar la racionalidad moderna como superior a la mítica porta consecuencias políticas significativas; y en algún caso negativas. Concretamente dicha forma de racionalidad ha producido resultados intuitivamente irracionales como, por ejemplo, el desastre ecológico. Las éticas racionales no dejan de ver a la tierra como medio para un fin -el bienestar humano- por lo que no abandonan el antropocentrismo, ni ofrecen una perspectiva alentadora para superar la crisis ecológica. En cambio, las éticas del mito son más eco-amigables, integran al ser humano con la naturaleza. Tal vez las éticas del mito nos ofrezcan buenas razones para detener el irracional desarrollo. El mito, entonces, deviene extrañado. 


\section{LA RACIONAL Y NECESARIA EXCLUSIÓN DE LOS MITOS}

Dos lecturas se pueden proponer respecto a la presencia o ausencia de los mitos respecto de la política. La primera, una corriente mayoritaria, señala una paulatina exclusión de los mitos por razones de irracionalidad y en pro de la convivencia entre culturas dispares. La segunda, corriente minoritaria, constata la incorporación de los mitos en contextos específicos: a favor de ideologías o nacionalismos.

La primera lectura explica el progresivo destierro del mito de la política. El creciente ascenso de la razón moderna, técnico científica del tipo cartesiana, como forma privilegiada de relación de la persona con su entorno, opacó progresivamente el mito, la religión, los sentimientos, etc ${ }^{1}$. Para gran parte del mundo contemporáneo, ser racional ha devenido pensar instrumentalmente. Esta forma de racionalidad se justifica principalmente por la dominación del entorno natural y el aumento de los beneficios económicos. Otras formas de racionalidad, otros posibles usos o sentidos de la razón, son menospreciados en diversos ámbitos. Nos interesa analizar particularmente el político.

Además, algunos mitos eran peligrosos y/o no podían alentar y/o garantizar la convivencia en situaciones de pluralidad. Conviene solapar religión y mito por un momento. En los orígenes de la democracia moderna, se encuentran hechos tortuosos como las Guerras de Religión de Europa (Rawls 2001a, Shklar 1990). Sendos credos cristianos se enfrentaron entre ellos por razones tan políticas como religiosas. En el mundo medieval, la unicidad religiosa estaba garantizada por la fuerza política de la Iglesia Católica. Pero, desde el siglo XVI, no fue posible mantener tal predominio. Estallaron guerras entre diversas versiones del cristianismo. Proclamar el propio credo religioso como el único verdadero hizo inviable la convivencia. Fue necesario recurrir a una salida ético-política: relegar la religión a lo privado. El escenario político debe

\footnotetext{
${ }^{1}$ Para ser justos con la historia de la filosofía, la racionalidad promovida por Descartes ha sido dominante en buena parte del mundo moderno. Pero no ha sido la única. Ha habido siempre debates internos, o al menos corrientes minoritarias que abogaban por una comprensión más amplia de la razón. Por citar solo un ejemplo, Pascal -contemporáneo de Descartes- afirmaba que el "corazón tiene razones que la razón no entiende" (2001).
} 
proclamarse neutral respecto de las religiones ${ }^{2}$. El estado administra justicia entre todos los grupos sociales, divididos por cuestiones religiosas o de otra índole. La política debe ser neutra a fin de no favorecer un grupo -o un credo- particular.

Los mitos corrieron una suerte semejante a las creencias religiosas. Los teóricos más importantes en la filosofía política contemporánea, como John Rawls $(2001$ b) o Jürgen Habermas $(1998,2000)$ han coincidido en la necesidad de racionalizar el debate. Buscar argumentos que todos los grupos implicados puedan reconocer como universalizables, esto es, racionales. Ambos suscriben una sociedad democrática liberal donde el valor supremo a cuidar es la libertad de todos los miembros. Los mitos, siendo parroquiales o étnicos, son desterrados al mundo privado. Aunque públicamente -más precisamente políticamente- irrelevantes; pueden seguir guiando la vida de muchas personas o pueblos en el espacio privado.

En suma, con relación a esta primera lectura, habría que enfatizar lo siguiente: la esencia normativa de la democracia actual exige que gane el mejor argumento, el que todos lo puedan entender y consentir racionalmente como más propenso al bien común. Se da por supuesta la existencia de una razón universal. La finalidad es que se garantice la pluralidad, la convivencia de los distintos, que nadie pueda imponer su visión o cosmovisión sobre el resto.

Una segunda lectura sostiene que los mitos han sido reactualizados y reutilizados por líderes políticos o sociales. Sorel afirmaba que el mito es poderoso para la política pues apela a la emotividad (1978). En todo el globo, los nacionalismos se sostienen sobre sus propios mitos, buenos o malos. La visión de los fascismos europeos del XX, quienes promueven una raza superior, calza ciertamente con la categoría de mito. En el contexto latinoamericano, tenemos también muchos ejemplos. Por un lado, en el Perú, las élites criollas que lograron la independencia de España tenían una relación ambigua con las poblaciones indígenas y sus

\footnotetext{
${ }^{2}$ Ciertamente, la neutralidad era supuesta o una idealización. Es evidente que la génesis y ciertos principios políticos que orientaban los estados europeos estaban teñidos profundamente por el cristianismo aunque se declarasen plurales, laicos, o aconfesionales.
} 
cosmovisiones. Idealizaron el mundo andino, querían formar una nación a la altura del legendario pasado incaico. Al mismo tiempo, despreciaban al indígena real (Méndez 2000). Por otro lado, los movimientos sociales apelaban al mesianismo inca, como si el mundo andino pre hispánico fuese el paraíso de la equidad y la justicia (Flores 1987). He calificado a esta segunda lectura como minoritaria pues es decreciente, aunque pueda haber excepciones. No necesariamente desaparecerá esta forma de uso.

Parece un hecho que en general se apela cada vez menos al mito en los contextos políticos, especialmente cuando la economía se vuelve el sensor del desarrollo social. El mito puede ser un obstáculo. Cito un ejemplo peruano. Durante su segundo mandato presidencial (20062011), Alan García criticaba reiterativamente las cosmovisiones ancestrales o míticas porque eran típicas del "Perro del hortelano". En alusión a la fábula de Esopo, García reprochaba a los pueblos originarios que utilizaban sus creencias míticas para oponerse a la minería. Los calificaba como enemigos de la inversión y el desarrollo. No disfrutan ni dejan disfrutar. Decía García: "la demagogia y el engaño dicen que esas tierras no pueden tocarse porque son objetos sagrados y que esa organización comunal es la organización original del Perú, sin saber que fue una creación del virrey Toledo para arrinconar a los indígenas en las tierras no productivas" (2007). Los indígenas habrían sido engañados por sus propios mitos y otros inventados posteriormente. Luego, fueron situados en posiciones desventajosas -desde el punto de vista económico- que ahora idolatran. La siguiente cita más extensa confirmaría esta interpretación. Al hablar de los enemigos del Perú, García decía:

En tercer lugar [debemos] derrotar las ideologías absurdas panteístas que creen que las paredes son dioses y el aire es dios. En fin, volver a esas fórmulas primitivas de religiosidad donde se dice "no toques ese cerro porque es un Apu y está lleno del espíritu milenario" [...] Bueno si llegamos a eso, entonces no hagamos nada: ni minería. "No toques esos peces porque son criaturas de dios y son la expresión del dios Poseidón". Volvemos a, digamos, a este animismo primitivo ¿no? Yo pienso que necesitamos más educación, pero eso es un trabajo de largo plazo [...] Usted puede ir a cualquier lugar donde la población [...] y de acuerdo a su educación dice "no me toque a mí esta zona que es un santuario". Y uno pregunta: ¿santuario de qué? Si es un santuario de medio ambiente, ¡santo y bueno! "Es un santuario porque ahí están las almas de los antepasados" ¡Oiga! las almas de los antepasados están en el paraíso seguramente. ¡No están ahí! Y deje usted que los que ahora viven se nutran, 
obtengan trabajo en la inversión en esos cerros. De manera que es un largo trabajo, es decir, que estemos avanzando no significa que todas nuestras formas un poco antiguas de pensamiento hayan sido superadas (2011).

El primer punto que vale la pena destacar del texto citado es el cambio de un mito prehispánico por uno religioso judeocristiano. Dice que la montaña puede explotarse porque no es un santuario o cementerio de los antepasados, puesto que las almas "están en el paraíso seguramente". ¿Por qué un indígena no podría decir que el paraíso es un mito para él? ¿Por qué es primitivo afirmar que la montaña es sagrada, pero no los es la existencia del paraíso? ¿Un mito andino o amazónico es de por sí inferior a uno judeocristiano? El segundo punto es más discreto. En el texto reina un aire de superioridad y desprecio descarado que le hace un favor sutil a cierta cosmovisión. Para García, la economía no es mito; es realidad. Su visión, maximización de beneficios, es un objetivo racional que no se puede discutir. Aquello que detenga el desarrollo económico debe ser superado por primitivo y atrasado. Pero García desconoce que ese modelo de desarrollo que defiende ha sido llamado mito del progreso. Para sus críticos este mito hace referencia precisamente a una cosmovisión que se proclama como auténticamente racional y moralmente buena ¿La modernidad occidental y sus desarrollos son moralmente superiores a visiones tradicionales en todos sus aspectos? En el siglo XX, dolorosas experiencias globales han mostrado la sinrazón del mito del progreso. Cito algunas: una economía que genera desigualdad sin par -no solo en cuanto a recursos materiales sino, por ejemplo, también respecto del poder-, el desarrollo tecnológico utilizado en las guerras, la crisis ecológica más dramática en la historia de la humanidad.

\section{EL RETORNO DEL MITO}

Acabamos de ver los motivos por los que los mitos tienden a ser excluidos de la deliberación pública, aunque podrían seguir valorados en el ámbito privado -siempre que no estorben la argumentación racional política, ni sus fines económicos. Desplegaré ahora una defensa del mito en tres niveles. Primero, se relativiza la racionalidad que está detrás de la exclusión. Segundo, se subraya el derecho de los pueblos a promover su identidad y sus mitos. Tercero, se evalúa la posible ganancia éticopolítica al reincorporar los mitos para guiar los asuntos comunes. 
Primero, preguntemos si tales motivos para la exclusión son racionales o, en todo caso, a qué razón obedecen. Algunos autores latinoamericanos han ensayado una serie de argumentos al respecto. Augusto Sánchez, por ejemplo, sostiene que la esfera pública debe ser genuinamente plural para sociedades donde el mito, el rito, el símbolo y otros, son tan presentes como el llamado discurso racional (2012). Por genuinamente plural podemos entender no solo la diversidad cultural o política tipo ser de derecha o izquierda, o nacionalista o cosmopolita. Existe una pluralidad o variedad más profunda o compleja: la coexistencia de diversas racionalidades. La diversidad política tipo ser de derecha o izquierda puede llevar a callejones sin salida en la deliberación, sobre todo si las partes no reconocen el valor de los principios y argumentos de sus oponentes. Pero en general tienen en común la apelación a una misma racionalidad. ¿Qué pasa cuando no se trata de diversidad -simplefrente a opciones políticas sino de una profunda porque las racionalidades en juego son diferentes? Entre estas otras racionalidades y en buena parte de Latinoamérica, destaca aquella identificada con el mito antes que con el razonamiento instrumental.

Al cuestionarnos si un argumento moral inspirado en un mito puede competir racionalmente con, por ejemplo, un razonamiento universalista de tipo kantiano ${ }^{3}$, estamos enfocando la atención a la comparación misma. Pero existe un supuesto previo no evidenciado: no se discute desde dónde se debe dirimir la cuestión. Qué sujeto o qué racionalidad será la que juzga si un mito andino es tan racional como el imperativo categórico kantiano. Cuando la academia, los politólogos, u otros grupos abandonan el mito, lo hacen porque abrazan una forma de racionalidad que consideran más valiosa, más útil, más verdadera, o simplemente la única forma de pensar racionalmente.

En un segundo nivel, negarle un espacio al mito en la deliberación política significaría negar la participación de los pueblos indígenas como son. ¿Por qué exigirles que para ser escuchados dejen de ser indígenas?

\footnotetext{
${ }^{3}$ Kant pretendía que algunos de sus postulados morales fueran evidentes o deducibles desde la razón, a la que se consideraba única y universal (1977b). El mandato moral de no robar es tan universal -desde la razón más que desde la experiencia- como 1+1=2. El resultado de la suma debe ser aceptado por todos los seres racionales como verdadero porque la razón es una sola. El robar no puede ser una acción moral porque ningún ser racional podría desear racionalmente un mundo donde todos se roben mutuamente. No tiene sentido ni lógico ni moral.
} 
Tanto las teorías democráticas como sus implementaciones reales no son culturalmente neutras. Prefieren valores del dialogo democrático en versión occidental en vez de los valores políticos contados por mitos y costumbres ancestrales. Pero al indígena se le exigiría que hable en la lengua de otro, con el vocabulario de otro, desde la cosmovisión de otro. El modelo teórico de Rawls no tendría problema en que cada grupo social aliente los valores democráticos por sus propias razones o creencias, incluso las míticas (2001b). Pero cada cual podría aportar sus ideas al razonamiento público siempre que estas sean traducidas al lenguaje político racional y común cuando se trata de un tema público de interés general. Si no se pueden traducir hacia valores o argumentos democráticos universales, prácticamente sirven poco. Pero, podríamos preguntar a Rawls: ¿por qué son los pueblos oriundos quienes deben traducir sus razones? Es más ¿qué pasa cuando los argumentos míticos no son traducibles al lenguaje occidental político? En este segundo nivel, ampliar el espacio y el modo de deliberación pública para incluir el pensamiento mítico podría considerarse una cuestión de derechos. No hacerlo sería menospreciar la identidad de aquellos potenciales participantes. Ciertamente, en las últimas décadas los pueblos indígenas exigen reconocimiento de su identidad. Esta demanda subraya su derecho a expresar su cosmovisión y que esta sea tomada en cuenta para definir los objetivos colectivos.

Recapitulemos antes de pasar a un tercer nivel de mi defensa. El primero señala que la exclusión de un mito podría no sostenerse ya que se hace en el fondo al suscribir acríticamente una forma de racionalidad -la racional moderna- que podría ser considerada incluso otro mito desde de las perspectivas que precisamente rechaza. El segundo afirma que aceptar los mitos en el debate público sería una conclusión natural de reconocer a los pueblos indígenas como ciudadanos con su propia identidad. En tanto que no están obligados a occidentalizarse, no tendrían por qué abandonar sus mitos al deliberar públicamente. El tercer argumento, que introducimos ahora, pone el acento en la ganancia ética por la inserción de mitos. ¿No estamos perdiendo algo fundamental para la convivencia democrática y la búsqueda de fines colectivos cuando excluimos los mitos? Veamos. 
Un motivo para excluir a los mitos es que el todo, el estado en conjunto, podría no valorarlos porque ni siquiera entiende aquello que es propio de un sub-grupo particular. Atenta contra los demás grupos el que una comunidad, llamémosle una minoría étnica ${ }^{4}$, insista en que su mito sea escuchado, entendido, apreciado, e implementado a través de políticas públicas ${ }^{5}$. Este era el argumento para excluir a las religiones al momento de moldear el Estado. Al aparecer era necesario desterrar el mito -como la religión- al ámbito privado. Preguntemos ahora ¿no se está privando de un bien a toda la comunidad más amplia al excluir esa creencia minoritaria? ¿No corremos el riesgo de perder sabiduría ética y política cuando la mayoría excluye a los mitos de la minoría alegando que no los entiende o son irracionales?

Para ilustrar esta defensa, especulemos sobre uno de los problemas éticos y políticos más graves que viven las democracias 0 , mejor dicho, toda la humanidad: la crisis ecológica. Una de las corrientes éticas más importantes es la de Kant. Algunos de sus postulados han inspirado la implementación de un orden jurídico que proteja los Derechos Humanos - la realización de un sistema interestatal que asegure la paz entre los pueblos (1977a, 1977b). Kant señalaba que el ser humano es la encarnación misma de la ley moral. Mientras que todo en el universo bienes materiales, la inteligencia, el poder-son medios buenos o malos según los objetivos o fines de un sujeto, el ser humano es el único ser capaz de tener fines. El ser humano es el único ser con razón y esta la permite que tenga objetivos o fines. Por tanto, es el único ser que es fin en sí mismo, mientras que todo lo demás -la naturaleza incluso- queda relegado a ser medio para los fines de la humanidad. La razón reconoce este argumento como verdadero ${ }^{6}$. Pero ¿el respeto o aprecio al ser

\footnotetext{
${ }^{4}$ El termino minoría étnica puede ser acertado en algunos contextos pero equívoco en otros. Por ejemplo, hacia la mitad del siglo pasado en Perú la gran mayoría de la población no tenía el español como primera lengua. Pese al mestizaje, los grupos quechuas no eran minorías. Hoy parece que sí lo son.

${ }^{5}$ La implementación de un mito -ejemplo conceder feriados oficiales por fiestas tradicionales como se suele hacer con las fiestas religiosas, Navidad o Semana Santa- es el último paso de la cadena. En muchos casos los mitos no son siquiera escuchados por la opinión pública y sus intérpretes -poder ejecutivo y parlamento.

${ }^{6}$ Ver nota 3. Este sería uno de los típicos argumentos kantianos que supuestamente se derivan por completo de principios racionales y debe ser evidente para cualquier ser con razón. Es tan evidente como $1+1=2$, a unque es cierto que tal vez un ser racional requiere ejercitar su razón para comprender esta verdad, más compleja que una suma simple.
} 
humano en tanto único sujeto racional o fin en sí mismo es suficiente para lograr cambios sustanciales respecto a la relación entre la humanidad y la naturaleza? ¿Otras éticas llamadas racionalistas han ofrecido buenas razones para evitar la crisis ecológica o salir de ella? Aunque no puedo desarrollar una respuesta pormenorizada, considero que la mayoría de éticas racionalistas caen en la trampa antropocéntrica, probablemente porque la racionalidad que las propone y valora también lo es. Por tanto ¿debemos abandonar ese tipo éticas? No necesariamente, pero sí escuchar otras racionalidades, como las míticas, y sus éticas asociadas.

El mito puede ofrecer una alternativa de contenido ético y político superior para fines ecológicos. Hoy el razonamiento pro medio ambiente que todavía prima en las agendas internacionales es todavía muy antropocéntrico. Los organismos intergubernamentales o las empresas transnacionales -a quienes se obliga crecientemente a ser más responsables ambientalmente- reconocen que la actuación de las últimas décadas podría acabar con el mundo necesario para que la humanidad perviva. Actuar más responsablemente significaría que la acción sea compatible con la continuidad de la especie humana, pero no se le reconoce a la naturaleza un derecho propio. Los mitos, al contrario, son muy pro-naturalezao eco-amigables. Pienso en una historia relativamente exitosa. En Canadá los ambientalistas tenían serios problemas para movilizar a la opinión pública respecto de la deforestación de uno de los bosques vírgenes templados más grandes del mundo situado en la costa del Pacífico. Una estrategia inteligente fue re-imaginar la región, recrear un mito. "Había sido llamada las zonas de abastecimiento de madera en costa central y costa norte. Un paso inteligente fue renombrarla como la Selva del Gran Oso. Así, el mítico espíritu del oso se convirtió en el símbolo de una región transformada: ya no es sólo una fuente de recursos sino un ecosistema remoto y sagrado" (Zachariah 2016: p. 20).

La perspectiva ecológica de los mitos es poco aprovechada por la política de los Estados en parte porque es muchas veces contraria a los intereses de las grandes corporaciones. Pongamos el ejemplo de la Conferencia de las Naciones Unidas sobre Desarrollo Sostenible Rio+20 
del año 2012 ${ }^{7}$. La Conferencia fue íntegramente dedicada a la sostenibilidad, pero esta se entendía sobre todo en términos antropocéntricos. La expresión central del documento, la meta moral y política de los líderes del globo era la economía verde, que viene defina del siguiente modo:

\begin{abstract}
En su forma más básica, una economía verde sería aquella que tiene bajas emisiones de carbono, utiliza los recursos de forma eficiente y es socialmente incluyente. En una economía verde, el aumento de los ingresos y la creación de empleos deben derivarse de inversiones públicas y privadas destinadas a reducir las emisiones de carbono y la contaminación, a promover la eficiencia energética así como en el uso de los recursos, y a evitar la pérdida de diversidad biológica y de servicios de los ecosistemas. Dichas inversiones han de catalizarse y respaldarse con gasto público selectivo, reformas políticas y cambios en la regulación. El camino hacia el desarrollo debe mantener, mejorar $y$, donde sea necesario, reconstruir el capital natural como activo económico fundamental y fuente de beneficios públicos, especialmente para las personas desfavorecidas cuyo sustento y seguridad dependen de la naturaleza (PNUMA 2012a: p. 2$)^{8}$.
\end{abstract}

Por un lado, el documento final de dicha Conferencia menciona explícitamente la necesidad de respetar y promover los derechos e intereses de los pueblos indígenas (PNUMA 2012b). Además, se propone sumarlos como agentes del desarrollo sostenible. No obstante, casi no se incorporan elementos de sus cosmovisiones de la naturaleza para enfrentar el problema. Es cierto que un numeral del documento final, firmado por la mayoría de líderes oficiales del planeta, dice: "Reconocemos que el planeta Tierra y sus ecosistemas son nuestro hogar y que 'Madre Tierra' es una expresión común en muchos países y regiones, y observamos que algunos países reconocen los derechos de la naturaleza en el contexto de la promoción del desarrollo sostenible" (2012b: p. 33). Tal referencia, recuperar el mítico reconocimiento de la Tierra como madre -o Pachamama, para el mundo andino- parece saludable. No obstante, temo que muy conscientemente el documento elude entrar en más detalle. En Sudamérica es muy extendida la creencia en la Pachamama. La tierra es concebida como madre, fuente de vida, sostén y sustento. Si la Tierra es Madre y algunos de sus hijos-digamos,

\footnotetext{
${ }^{7}$ Rio+20 -cuyo nombre se debe a que conmemora la Cumbre de la Tierra en Rio de Janeiro1992ha sido el evento de más alto nivel en los últimos años dentro de la estructura de las Naciones Unidas para lograr acuerdos sobre el desarrollo sostenible.

${ }^{8}$ Este fue el documento preparatorio. La expresión economía verde también se encuentra al centro del documento final, El futuro que queremos. (PNUMA 2012b).
} 
los pueblos originarios- buscan protegerla, ¿no deberíamos esperar que los líderes del mundo y las transnacionales también lo hagan con las categorías y ahínco de aquellos? Pero no lo hacen. En todo caso, empresarios y políticos que saquean y destruyen la naturaleza serían hijos pródigos: aprovechan la riqueza de la madre sin importar su suerte aludiendo a una parábola cristiana -¿otro mito? La referencia positiva en el documento de la Conferencia a esa visión ancestral es más bien un modo político para congraciarse con los pueblos indígenas, las ONGs y sociedad civil que simpatizan con esa visión. Pero el modelo económico, protegido por el sistema internacional de Estados, no puede darse el lujo de creer de verdad que la Tierra es nuestra madre común. Mientras tanto, tal mito sigue vivo: es reactualizado constantemente en Sudamérica a través de diversas manifestaciones y ritos -como el pago a la tierra, la fiesta de la pachamama, entre otros. Pero este apego al mito queda en el mundo privado. Tomarse en serio a la Madre Tierra implicaría perder o, más bien, dejar de ganar demasiado, lo cual es contrario a los intereses del capitalismo vigente. La maternidad de la Tierra solo puede ser bella retórica y los líderes no acompañan a los pueblos indígenas.

\section{CONCLUSIÓN}

He defendido la inclusión de los mitos en la deliberación política. Pero ciertamente no deslegitimo las razones que han llevado a su exclusión progresiva. El razonamiento que conminaba el mito a las vivencias privadas de los pueblos indígenas sigue parcialmente vigente. No podemos afirmar ingenuamente que todos los mitos deban ser bienvenidos por el simple hecho de ser mitos con los que algunas poblaciones se identifican. ¿Qué pasa, por ejemplo, con mitos que justifican superioridad racial, la xenofobia o -muy universalmente- el sexismo? Algunos mitos -o sus utilizaciones conscientes- pueden ser peligrosos. En el artículo hemos mencionado al fascismo europeo y al nacionalismo criollo latinoamericano como ejemplos de mitos que sirvieron para excluir y menospreciar personas reales. No es difícil imaginar otros ejemplos. Por ello el mito ha devenido extraño para la política.

De todos modos, las democracias contemporáneas podrían mostrar un signo de madurez política permitiendo la incorporación de ciertos mitos. 
Esta apelación se hace más urgente en contextos como los latinoamericanos donde muchos pueblos originarios aún albergan mitos con orgullo. Ciertos mitos pueden ser fuente de sabiduría y guía para la acción práctica. Queda pendiente la cuestión sobre cómo distinguir entre mitos útiles y mitos peligros. ¿Son los propios principios democráticos igualdad, tolerancia, entre otros- quienes resolverán la incorporación? Dejo planteada la interrogante. Me interesaba más discutir la utilidad del mito. Creo que puede ser fructífera y se aprecia mejor precisamente cuando la razón excluyente nos deja sin respuestas. Este es un buen motivo para que extrañemos su presencia. Pasemos así, en la política, de la visión del mito extraño a la del mito extrañado.

\section{BIBLIOGRAFÍA}

Flores, Alberto. (1987) Buscando un inca. Identidad y utopía en los Andes. Segunda edición. Lima: Horizonte.

García, Alán. (2007) "El síndrome del perro del hortelano". El Comercio. Lima: 28 de octubre de 2007.

García, Alán. (2011) Entrevista concedida a Cecilia Valenzuela. Dirección: https://www.youtube.com/watch?v=WX1ZVkdDIWE. Consulta: 21 de diciembre de 2016

Habermas, Jürgen. (1998) Facticidad y validez. Madrid: Trotta.

Habermas, Jürgen. (2000) Aclaraciones a la ética del discurso. Madrid: Trotta.

Méndez, Cecilia. (2000) Incas sí, indios no: apuntes para el estudio del nacionalismo criollo en el Perú. Lima: IEP.

Kant, Inmanuel. (1977a) La paz perpetua. Buenos Aires: Porrúa.

Kant, Inmanuel. (1977b) Fundamentación metafísica de las costumbres. Buenos Aires: Porrúa.

Pascal, Blaise (2001) Pensamientos. Madrid: Valdemar.

PNUMA (2012a) Hacia una economía verde. En: Programa de las Naciones Unidas para el Medio Ambiente (PNUMA). Dirección:

http://www.unep.org/greeneconomy/Portals/88/documents/ger/GER_synthesis _sp.pdf Consulta: 30 de junio de 2012. 
PNUMA (2012b) El futuro que queremos. En: Programa de las Naciones Unidas para el Medio Ambiente (PNUMA). Dirección: http://www.un.org/es/sustainablefuture/ Consulta: 30 de junio de 2012.

Rawls, John. (2001a) Lecciones sobre la historia de la filosofía moral. Barcelona: Paidós.

Rawls, John (2001b) "Una revisión de la idea de razón pública". En: Rawls, John. El Derecho de gentes. Barcelona: Paidós: pp. 157-203.

Sánchez, Augusto. (2012) La esfera pública intercultural: Una mirada hermenéutica para contextos multiculturales. Editorial Académica Española.

Shklar, Judith (1990) Vicios ordinarios. México D.F: FCE.

Sorel, Georges. (1978) Reflexiones sobre la violencia. Buenos Aires: La Pleyade.

Zachariah, Kuruvila; Zachariah, Lois (2016) "Ecología Integral: Estudio de un caso y una reflexión espiritual". En: Progressio, suplemento 72, 2016, pp. 18-25. 